\title{
Association between body composition and stair negotiation ability among individuals $>55$ years of age: a cross-sectional study
}

This article was published in the following Dove Press journal:

Clinical Interventions in Aging

18 August 2017

Number of times this article has been viewed

\author{
Renata Maciulis Dip \\ Marcos AS Cabrera \\ Sabrina Ferrari Prato \\ Department of Public Health, \\ Postgraduate Program in Public \\ Health, State University of Londrina \\ (UEL), Londrina, Paraná, Brazil
}

Background: Loss of muscle strength exerts a considerable impact on the quality of life and mortality of older adults. The present household survey study measured body composition and muscle strength with the aim of analyzing the roles of low lean mass, low muscle strength and obesity in stair negotiation ability and the effect of comorbidities on the relationship between body composition and functional capacity.

Methods: Body composition was assessed using bioelectrical impedance analysis and muscle strength was assessed with a hand grip dynamometer. The study population comprised individuals $>55$ years of age from a medium-sized Brazilian municipality. The sample included 451 participants.

Results: A total of 368 subjects were interviewed; their ages varied from 56 to 91 years. Among males, low muscle strength was associated with stair negotiation difficulty independent of muscle mass, age and obesity but muscle mass was not. However, when we analyzed comorbidities and body composition jointly, chronic lower limb pain and obesity were independently associated with stair negotiation difficulty but body composition and age were not. Among women, after comorbidities were included into the model, low muscle strength and obesity remained associated with stair negotiation difficulty as chronic lower limb pain and depression. The relationship between muscle function and comorbidities is discussed in this article.

Keywords: sarcopenia, obesity, depression, older people

\section{Introduction}

Preservation of the functional capacity (FC) is essential for the quality of life of older adults. FC can be defined as the ability of older adults to meet the physical demands of everyday life, which range from the most basic activities needed for independent living to more complex actions demanded by the daily routine. ${ }^{1}$ Among women, decline in FC seems to affect mobility first, whereas more basic functions, such as the basic and instrumental activities of daily living, become impaired at a later date. ${ }^{2}$

Among older adults, FC might be influenced by countless factors, such as musculoskeletal, mental or cardiovascular diseases, nutritional status and body composition.

Mobility is an important component of FC with a significant influence on the ability to perform the activities of daily living in an independent manner. Mobility can be evaluated based on the observation of stair negotiation. This difficulty might represent the earliest stage of motor disability for most people. ${ }^{3,4}$ Additionally, observation of stair negotiation is a quick and valid method to assess the risk of functional decline of older adults living in the community. ${ }^{5}$
Correspondence: Renata Maciulis Dip Universidade Estadual de Londrina, Avenida Robert Koch, 60 Vila Operária, CEP 86038 350, Londrina, Paraná, Brazil Tel +55 439 983I 9000

Email renatadip@yahoo.com.br 
Body composition indicates the amount of body fat and lean mass that compose the total body mass. Bioelectrical impedance analysis (BIA) is a quick, noninvasive and relatively inexpensive method to assess body composition. ${ }^{6}$ A low-intensity electrical current is passed through the subject's body and the BIA device measures the resistance opposed to the current flow. The value of the measured resistance is used in equations that estimate body fat and lean mass. This method is a good option for the assessment of body composition in fieldwork.

FC is affected by both excess body fat and a deficit in lean mass. However, the exact role each component plays is the subject of much debate. Moreover, muscle strength seems to be more significant for FC preservation than muscle mass. Muscle mass is essential for the regulation of wholebody metabolic balance but is not the principal variable to FC. Furthermore, muscle strength depends not only on muscle size but also on physiologic factors such as neural activation, ${ }^{7}$ mitochondrial alterations, ${ }^{8}$ changes in interleukins and inflammation, ${ }^{9-11}$ changes in protein synthesis and degradation. ${ }^{12}$ Neuromuscular function seems to be a critical factor for maintaining muscle strength and physical independence in the elderly. ${ }^{7,13}$

\section{Objectives}

The present article analyzes the role of body composition in the FC of older adults living in the community based on their stair negotiation performance and the influence of comorbidities on this association.

\section{Methods}

\section{Study design, setting, participants and data collection}

The present cross-sectional study was based on a household survey conducted from April through August 2012 at a medium-sized city in southern Brazil. The study population consisted of all individuals aged $\geq 56$ years who had previously participated in the VigiCardio population-based study. ${ }^{14}$ From 501 eligible subjects from the first survey (VigiCardio), 36 subjects were excluded because BIA was contraindicated (due to a cardiac pacemaker, metallic prosthesis, amputated limbs or considerable edema). Additionally, 14 individuals died between the beginning of the original project and the onset of the present study. We aimed to use a populationbased sample and not a convenience one. To minimize loss of participants, this research was based on a household survey. The sample was constituted by 451 subjects (192 males and 259 females). The subjects were divided into two groups on the basis of age: $56-64$ years and $\geq 65$ years. There are two reasons for this: first, to separate the ones who can be considered "old people" from the young adults and second, almost halth of the sample composed each group, and we wanted to see the differences that aging could bring to the older group.

\section{Variables, data source and efforts to address potential sorts of bias}

Stair negotiation ability was assessed by the question "Do you have difficulty walking on stairs?" All individuals who reported any difficulty walking on stairs and/or needing a caregiver's help were classified as dependent.

The variables included in the survey are:

- Comorbidities: conditions likely to impair the stair negotiation ability were included even when not associated with muscle strength and muscle mass abnormalities, such as depression, obesity, heart failure (HF), chronic obstructive pulmonary disease (COPD) and chronic lower limb pain; these conditions were reported by the subjects themselves or by a relative.

- Body composition

- Body weight (measured at home): the subjects' body masses were measured using a portable electronic scale (Acqua SIM 09190; Plenna, São Paulo, Brazil) with a $100 \mathrm{~g}$ resolution and a maximum capacity of $150 \mathrm{~kg}$. The participants were asked to wear light clothes, remove their shoes and stand on the center of the scale platform without hand support.

- Height: it was measured using a portable stadiometer with a $0.1 \mathrm{~cm}$ resolution and $2 \mathrm{~m}$ maximum range.

- Lean mass: it was assessed via BIA using the BF-906 analyzer (Maltron, Essex, UK), which operates on one single frequency $(50 \mathrm{kHz})$ and does not measure reactance. Because BIA is sensitive to body water contents, assessments were performed according to the usual standards to minimize measurement error: fasting, no alcohol for $>8$ hours, no physical exercise for 24 hours and bladder voided (subject has voided before measurement). ${ }^{15}$ We requested Maltron to provide the equations used in the analyzer, but the company refused for reasons related to trade secret protection. Lean mass was categorized as low or normal; the individuals were classified as having a low lean mass when the corresponding value was within the lower quartile per gender (relative to the study population). Lean mass was estimated as the ratio of total lean mass (in kilograms) to squared height (in meters). The lower quartiles were calculated separately for the two groups: 56-64 years and $\geq 65$ years. The normal values for lean mass vary in 
the literature according to the method and ethnicity. ${ }^{6,16}$ However, in our country, there is a great miscegenation from black people, oriental people, European people and others. This hazards value standardization, and there are not established values for Brazilian people. The lower quartile was preferred to make comparisons in the present work.

- Obesity: individuals with a body mass index (BMI) $\geq 30.0 \mathrm{~kg} / \mathrm{m}^{2}$ were considered obese. ${ }^{17}$

- Hand grip strength: it was measured using the Saehan SH5001 hydraulic hand dynamometer (Saehan Corporation, Masan, Korea) following the guidelines formulated by the American Society of Hand Therapists: subject seated, shoulders adducted and neutrally rotated, elbow flexed at $90^{\circ}$, forearm in neutral and wrist between $0^{\circ}$ and $30^{\circ}$ of dorsiflexion. ${ }^{18}$ Accordingly with Roberts et al, ${ }^{19}$ there are other variables that can influence in this measure:

o Position: the Saehan SH5001 hydraulic hand dynamometer has five handle positions, and most participants used the second position. However, some people had larger hands and used the third position.

- Hand dominance: the participants used the dominant hand.

- Effort and encouragement: after the subject was positioned appropriately, the examiner said: "Are you ready? Squeeze as hard as you can". As the subject started to squeeze, the examiner said: "Harder! ... Harder! ... Relax".

- Interval between measurements: there was 1 minute interval between each of the three measures.

- Time of the day: although some authors report a circadian rhythm in grip strength, some of our measures were done in the morning and others in the afternoon.

- The mean value of three measures of grip strength was used. If the variation between the three measures was $>20 \%$, the highest measure would be used (but this case did not occur).

- The average grip strength values were separately calculated for the obese and nonobese groups. Because the grip strength tended to be higher among the obese participants, adjustment of the lower quartiles by the presence or absence of obesity was performed as an attempt to correct this source of bias. ${ }^{20}$ The lower quartile was categorized as "low muscle strength". Although there are some values of normal grip strength by age, ${ }^{21}$ this value varies according to ethnicities. Hence, we used the lower quartile to define "low muscle strength".

\section{Statistical analysis}

Statistical analysis was performed with the Epi Info version 3.5.4 software (Centers for Disease Control and Prevention, Atlanta, GA, USA). Males and females were analyzed separately due to wide differences in body composition and characteristics of the aging process. ${ }^{22}$ The sample was stratified into two groups according to age (56-64 years and $\geq 65$ years). The significance level was set to $95 \%$ in all tests. The chi-square test was used in comparisons by gender, and Fisher's exact test was used whenever necessary. The logistic regression model fit on the multivariate analysis considered variable difficulty in stair negotiation adjusted for age. Three models were presented: the first model was fit with three independent variables as follows: age ( $\geq 65$ years), lean mass (lower quartile) and muscle strength (lower quartile). In the second model, obesity was added and the third model included comorbidities.

\section{Ethical demands}

The present study complied with the ethical norms in force; approval was registered in the National System of Information on Human Research Ethics (CAAE no 0192.0.268.000-10). All participants signed an informed consent form, were aware of the voluntary nature of participation and were assured of the confidentiality of their personal data. At the end of the interviews, the subjects were communicated the results of their body composition and received orientations on actions to improve their body composition and muscle strength.

\section{Results}

From the 451 subjects of the sample (192 males and 259 females), many individuals (83 individuals) were not included due to the following reasons: subjects not found after three visits (20), subjects moved or were not located (17), subjects refused to participate (12), subjects admitted to the hospital during the data collection period (3) and subjects not found due to problems in the records (31). The final sample was constituted by 368 people (148 males and 220 females).

The average age of the participants was 65.4 years (standard deviation $=7.1$ ); no difference in the age range was found between genders. Schooling and social level were similar in both genders. The prevalence of depression; continuous pain in the hands, knees or feet; difficulty in stair negotiation; visual impairment and falls was higher among the females than among the males. Additionally, the prevalence of obesity was higher among the females $(36.4 \%$ vs $25.0 \%, P=0.03)$.

Approximately $42 \%$ of the females and $26 \%$ of the males reported difficulties in stair negotiation $(P=0.003)$. 
No difference as a function of age was found among the males, whereas difficulties were more frequent among females $>64$ years compared to younger females.

A low lean mass was defined in lower quartile values. These values were $\leq 17.80 \mathrm{~kg} / \mathrm{m}^{2}$ and $\leq 17.18 \mathrm{~kg} / \mathrm{m}^{2}$ for the younger males (56-64 years) and older males ( $\geq 65$ years), respectively $(P=0.03)$. The corresponding values for the females were $15.74 \mathrm{~kg} / \mathrm{m}^{2}$ and $15.50 \mathrm{~kg} / \mathrm{m}^{2}$, respectively $(P=0.11)$.

The hand grip strength was significantly higher among the younger participants from both genders.

A low grip strength was defined as $\leq 32.0 \mathrm{~kg}$-force and $\leq 38.0 \mathrm{~kg}$-force for the nonobese and obese male subjects, respectively $(P<0.001)$. The corresponding values for the female participants were $\leq 20.0 \mathrm{~kg}$-force and $\leq 21.0 \mathrm{~kg}$-force for the nonobese and obese subjects, respectively.

Venn diagrams were plotted to analyze the overlap among individuals with a low lean mass, low muscle strength and stair negotiation difficulty (Figure 1). When individuals from both age range groups were analyzed jointly, the quartile values for low lean mass and low muscle strength differed as a function of the age range.

Approximately $45 \%$ of the males did not exhibit abnormalities in any of the three parameters assessed. Among the 81 males with some abnormalities (Figure 1), $\sim 50 \%$ of the subjects who reported stair negotiation difficulties did not have low muscle strength or a low lean mass. Half of the participants with low muscle strength reported stair negotiation difficulties, and 40\% had neither low lean mass nor stair negotiation difficulties.

The bivariate analysis of stair negotiation difficulty versus the remainder of the investigated variables showed that the difficulty was more frequent among the participants with hand grip strength values within the lower quartile and the participants with continuous lower limb pain, HF and visual impairment (Table 1).

In the multivariate analysis (Table 2), the first model showed that low muscle strength was associated with stair negotiation difficulty independent of age and a low lean mass (odds ratio $[\mathrm{OR}]=4.03,95 \%$ confidence interval [CI]: $1.73-9.37, P=0.001$ ). Obesity was added to the model next; muscle strength remained associated with the stair negotiation difficulty independent of all other factors ( $\mathrm{OR}=3.73,95 \%$ CI: $1.58-8.77, P=0.003)$. Obesity exhibited the following: 95\% CI: $0.97-6.7, \mathrm{OR}=2.47$ and $P=0.057$.

With an eye on clinical practice, comorbidities were included in the model (lower limb pain, HF, visual impairment and depression). Additionally, COPD was analyzed due to its relevance for physical activity. In this model, lower limb pain (OR $=5.10,95 \%$ CI: $1.96-13.29, P<0.001)$ and obesity ( $\mathrm{OR}=3.73,95 \% \mathrm{CI}: 1.24-11.29, P=0.02)$ were independently associated with stair negotiation difficulty. A similar relationship was not found for COPD, probably due to the fragility of this variable or because the subjects exhibited only milder degrees of the disease.

Approximately $35 \%$ of the females did not exhibit abnormalities in muscle strength, lean mass or stair negotiation ability. Among the females who did exhibit abnormalities, $65 \%$ reported difficulty negotiating stairs (Figure 1), although almost $50 \%$ of them did not exhibit low muscle strength or a low lean mass. Among the participants with low muscle strength, $65 \%$ reported stair negotiation difficulty and $30 \%$ reported having neither of the other two investigated abnormalities.
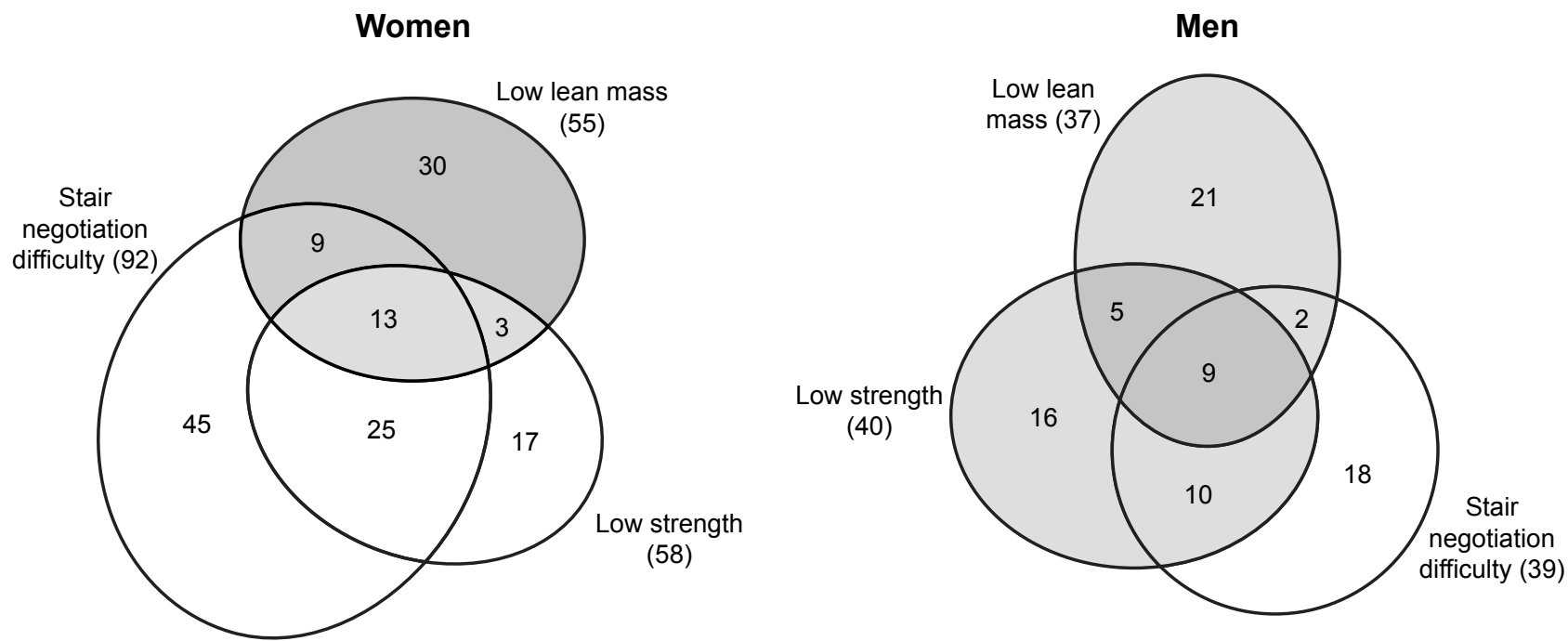

Figure I Venn diagrams showing the distribution of the participants in Cambé, Paraná, in 2012. 
Table I Distribution of the participants according to stair negotiation difficulty by gender in Cambé, Paraná, in 2012

\begin{tabular}{|c|c|c|c|c|c|c|}
\hline \multirow[t]{4}{*}{ Variable } & \multicolumn{6}{|c|}{ Stair negotiation difficulty } \\
\hline & \multicolumn{3}{|c|}{ Male gender } & \multicolumn{3}{|c|}{ Female gender } \\
\hline & \multicolumn{2}{|c|}{ Yes } & \multirow[t]{2}{*}{$P$-value } & \multicolumn{2}{|c|}{ Yes } & \multirow[t]{2}{*}{$P$-value } \\
\hline & $\mathbf{n}$ & $\%$ & & $\mathbf{n}$ & $\%$ & \\
\hline \multicolumn{2}{|c|}{ Age range, years } & & 0.41 & & & 0.008 \\
\hline $55-64$ & 16 & 41.0 & & 40 & 43.5 & \\
\hline$\geq 65$ & 23 & 59.0 & & 52 & 56.5 & \\
\hline Obesity & & & 0.10 & & & 0.002 \\
\hline Yes & 14 & 35.9 & & 45 & 48.9 & \\
\hline No & 25 & 64.1 & & 47 & 51.1 & \\
\hline \multicolumn{3}{|c|}{$\begin{array}{l}\text { Hand grip strength lower } \\
\text { quartile }\end{array}$} & $<0.001$ & & & $<0.001$ \\
\hline Yes & 19 & 48.7 & & 38 & 41.3 & \\
\hline No & 20 & 51.3 & & 54 & 58.7 & \\
\hline \multicolumn{3}{|c|}{ Lean mass lower quartile } & 0.75 & & & 0.87 \\
\hline Yes & 11 & 28.2 & & 22 & 23.9 & \\
\hline No & 28 & 71.8 & & 70 & 76.1 & \\
\hline \multicolumn{3}{|c|}{$\begin{array}{l}\text { Use of insulin or hypoglycemic } \\
\text { drugs }\end{array}$} & 0.37 & & & 0.01 \\
\hline Yes & 8 & 20.5 & & 20 & 21.7 & \\
\hline No & 31 & 79.5 & & 72 & 78.3 & \\
\hline Depressior & & & 0.17 & & & $<0.001$ \\
\hline Yes & 6 & 15.4 & & 37 & 40.2 & \\
\hline No & 33 & 84.6 & & 55 & 59.8 & \\
\hline \multirow{2}{*}{\multicolumn{3}{|c|}{$\begin{array}{l}\text { Continuous pain in hips, knees } \\
\text { or feet }\end{array}$}} & $<0.001$ & & & $<0.001$ \\
\hline & & & & & & \\
\hline Yes & 25 & 64.1 & & 63 & 68.5 & \\
\hline No & 14 & 35.9 & & 29 & 31.5 & \\
\hline \multicolumn{3}{|c|}{ Continuous pain in hands } & 0.38 & & & $<0.001$ \\
\hline Yes & 4 & 10.3 & & 35 & 38.0 & \\
\hline No & 35 & 89.7 & & 57 & 62.0 & \\
\hline $\mathrm{HF}$ & & & $<0.001$ & & & 0.14 \\
\hline Yes & 13 & 33.3 & & 10 & 10.9 & \\
\hline No & 26 & 66.7 & & 82 & 89.1 & \\
\hline COPD & & & 0.63 & & & 0.22 \\
\hline Yes & 10 & 25.6 & & 10 & 10.9 & \\
\hline No & 29 & 75.4 & & 82 & 89.1 & \\
\hline \multicolumn{3}{|c|}{ Past history/current cancer } & 0.52 & & & 0.90 \\
\hline Yes & 3 & 7.7 & & 7 & 7.6 & \\
\hline No & 36 & 92.3 & & 85 & 92.4 & \\
\hline \multicolumn{3}{|c|}{ Visual impairment } & $<0.001$ & & & $<0.001$ \\
\hline Yes & 8 & 20.5 & & 28 & 30.4 & \\
\hline No & 31 & 79.5 & & 64 & 69.6 & \\
\hline \multicolumn{3}{|c|}{ At least one fall in the past year } & 0.60 & & & 0.02 \\
\hline Yes & 7 & 17.9 & & 36 & 39.1 & \\
\hline No & 32 & 82.1 & & 56 & 60.9 & \\
\hline
\end{tabular}

Abbreviations: COPD, chronic obstructive pulmonary disease; HF, heart failure.

Obesity was not associated with low muscle strength among the females, but it did exhibit correlations with a low lean mass and stair negotiation difficulty.

In the bivariate analysis, stair negotiation difficulty was associated with hand grip strength in the lower quartile, use of hypoglycemic drugs, continuous lower limb pain, visual
Table 2 Multivariate analysis of factors associated with stair negotiation difficulty in 2012

\begin{tabular}{|c|c|c|c|c|c|c|}
\hline & \multicolumn{3}{|c|}{ Male gender } & \multicolumn{3}{|c|}{ Female gender } \\
\hline & OR & $95 \% \mathrm{Cl}$ & $P$-value & OR & $95 \% \mathrm{Cl}$ & $P$-value \\
\hline \multicolumn{7}{|l|}{ Model I } \\
\hline Age $>65$ years & 0.96 & $0.42-2.19$ & 0.91 & 1.56 & $0.86-2.85$ & 0.14 \\
\hline $\begin{array}{l}\text { Low muscle } \\
\text { strength }\end{array}$ & 4.03 & I.73-9.37 & 0.001 & 3.56 & I.78-7.II & $<0.001$ \\
\hline Low lean mass & 1.03 & $0.42-2.48$ & 0.96 & 0.63 & $0.32-1.24$ & 0.18 \\
\hline \multicolumn{7}{|l|}{ Model 2} \\
\hline Age $>65$ years & 1.08 & $0.46-2.54$ & 0.86 & 1.50 & $0.8 \mathrm{I}-2.77$ & 0.20 \\
\hline $\begin{array}{l}\text { Low muscle } \\
\text { strength }\end{array}$ & 3.73 & I.58-8.77 & 0.003 & 3.51 & I.73-7.12 & $<0.001$ \\
\hline Low lean mass & 1.43 & $0.55-3.76$ & 0.46 & 1.01 & $0.47-2.15$ & 0.98 \\
\hline Obesity & 2.47 & $0.97-6.27$ & 0.057 & 2.78 & I.45-5.35 & $<0.01$ \\
\hline \multicolumn{7}{|l|}{ Model 3} \\
\hline Age $>65$ years & 1.27 & $0.47-3.46$ & 0.64 & 1.51 & $0.77-2.95$ & 0.22 \\
\hline $\begin{array}{l}\text { Low muscle } \\
\text { strength }\end{array}$ & 2.75 & $0.95-7.99$ & 0.06 & 2.99 & $1.40-6.38$ & $<0.01$ \\
\hline Low lean mass & 1.43 & $0.47-4.39$ & 0.53 & 0.96 & $0.42-2.20$ & 0.93 \\
\hline Obesity & 3.73 & $1.24-11.29$ & 0.02 & 2.53 & $1.26-5.10$ & $<0.01$ \\
\hline Lower limb pain & 5.10 & $1.96-13.29$ & $<\mathbf{0 . 0 0 I}$ & 2.56 & $1.36-4.83$ & $<\mathbf{0 . 0 1}$ \\
\hline Heart failure & 3.12 & $0.95-10.31$ & 0.06 & 1.40 & $0.43-4.62$ & 0.58 \\
\hline $\begin{array}{l}\text { Visual } \\
\text { impairment }\end{array}$ & 3.34 & $0.54-20.50$ & 0.19 & 2.03 & $0.91-4.53$ & 0.08 \\
\hline COPD & 1.29 & $0.42-3.97$ & 0.65 & - & - & - \\
\hline Depression & 4.02 & $0.77-21.13$ & 0.09 & 2.78 & I.10-4.70 & 0.026 \\
\hline
\end{tabular}

Note: Bold values indicate $P \leq 0.05$.

Abbreviations: $\mathrm{OR}$, odds ratio; $\mathrm{Cl}$, confidence interval; $\mathrm{COPD}$, chronic obstructive pulmonary disease.

impairment, older age, obesity, depression, continuous pain in the hands and falls in the past year (Table 1).

In the multivariate analysis, the model that included the variables age, lean mass and muscle strength evidenced an association between muscle strength in the lower quartile and stair negotiation difficulty (OR $=3.56,95 \%$ CI: $1.78-7.11$, $P<0.001)$. After the addition of the variable obesity, the factors independently associated with stair negotiation difficulty were low muscle strength (OR $=3.51,95 \%$ CI: $1.73-7.12$, $P<0.001)$ and obesity (OR $=2.78,95 \%$ CI: $1.45-5.35$, $P<0.01)$. Following the inclusion of comorbidities in the model, low muscle strength and obesity remained associated with the variable of interest and lower limb pain $(\mathrm{OR}=2.56$, 95\% CI: 1.36-4.83, $P<0.01)$ and depression $(\mathrm{OR}=2.78$, $95 \%$ CI: $1.10-4.70, P<0.05)$ were independently associated with stair negotiation difficulty.

\section{Discussion}

This study helps to understand the complex interaction between low muscle mass and low strength in the elderly, evaluated by stair negotiation difficulty. When we analyzed just the influence of muscle mass, strength and age, only muscle strength was associated with stair negotiation difficulty. 
However, when we added obesity to the model, strength remained associated and obesity was associated too, but only for females. In the final model, when comorbidities were added, strength was not associated with stair negotiation difficulty and obesity remained associated for both males and females. Two important comorbidities are significantly associated with difficulty: lower limb pain for both males and females, and depression for only females.

In the InCHIANTI study, Cesari et $\mathrm{al}^{23}$ found that a slower walking speed was associated with health-related adverse effects. This finding suggests that measurement of the final outcome "fitness" is more relevant for the selection of highrisk populations than separate assessment of each individual variable because many factors are involved in FC loss.

The Venn diagrams plotted in the present study illustrate the complexity of the relationship between low lean mass, low muscle strength and function loss and call attention to the need to investigate additional factors that might interfere with performance in stair negotiation.

To evaluate the capacities of an individual is not a simple but a complex process. It is important to evaluate not only the physical impairment but also physical impairment in relation to the social situations and the final ability or disability. In this sense, Nagi disablement model reconfigures the perception of disability from a focus on physical limitations by defining disability more broadly as the product of a change in the expected interaction between the individual and the environment. ${ }^{24}$ In the male participants, low muscle strength was associated with stair negotiation difficulty independent of the lean mass level. Other authors also described muscle strength as a determinant of the stair negotiation ability. ${ }^{25}$ According to Clark and Manini, ${ }^{7}$ muscle strength is a better predictor of mobility decline than muscle mass.

When BMI was added to the multivariate analysis model, low muscle strength remained associated with the stair negotiation difficulty. Obesity also exhibited a relevant relationship, although the corresponding $P$-value was of borderline ( $P=0.057,95 \%$ CI: 0.97-6.27), perhaps due to insufficient statistical power. When comorbidities were included in the model, low muscle strength no longer behaved as an independent factor. Comorbidities, chronic low limb pain and obesity were specifically associated with stair negotiation difficulty independent of all other variables among the males. Thus, muscle strength is an important factor for males but is not independent of comorbidities. This finding is relevant for clinical practice.

According to Jenkins, ${ }^{26}$ although obese older adults are at a high risk for mobility decline, this effect partially depends on the presence of obesity-related comorbidities.
Patients with HF exhibit fatigue and dyspnea due to not only cardiorespiratory effects but also skeletal muscle abnormalities. ${ }^{27}$ The lack of association between HF and the stair negotiation difficulty found in our study might have been due to insufficient statistical power $(\mathrm{OR}=0.95-10.31$, 95\% CI: $0.95-10.31, P=0.06$ ).

The results corresponding to the females were different from the results obtained for the males in some regards.

In the bivariate analysis, stair negotiation difficulty was more frequent among the older females compared to the younger females $(P=0.008)$; in contrast, a difference as a function of age was not detected among the males. Although the aim of the present study was not to analyze differences in the aging process as a function of gender, interestingly, the negative influence of aging on the stair negotiation ability was more remarkable among the females. This effect might be partially accounted for by differences in body composition because the muscle strength and lean mass were lower among females than among males. This finding is a gender-specific constitutional characteristic that is partially due to the particularities of hormones and their actions in the body. Moreover, occupational factors might be involved (males might perform more physical activity at work than females).

In the EPIDOS study, Rolland et $\mathrm{al}^{28}$ found that obesity was more associated with difficulties in the performance of physical activities (eg, walking on stairs) than sarcopenia. These data partially agree with our data because in the present study, obesity was also independently associated with stair negotiation difficulty.

The investigated comorbidities that were more strongly associated with stair negotiation difficulty in females were chronic lower limb pain, depression and obesity.

Overall, the performance of daily activities depends on both physical and psychological aspects. The mechanisms underlying the relationship between depression and functional decline in older adults are complex and include neural, hormonal, immunological and motivational changes. ${ }^{29}$

Regarding chronic lower limb pain and osteoarthritis (OA), previous studies that did not assess body composition found a correlation between pain and difficulty performing daily activities. ${ }^{30}$ In this regard, females usually exhibited greater locomotion difficulties than males. ${ }^{31}$

The relationship between pain and stair negotiation difficulty is more complex than it seems due to not only movement limitations to avoid pain but also arthrogenic muscle inhibition. The latter is defined as the loss of full range of voluntary muscle contraction due to a joint disorder that sensitizes the joint receptors. Excessive pain and intra-articular fluid sensitize the capsule mechanoreceptors, which emit 
signals to spinal inhibitory interneurons that in turn inhibit alpha motor neurons and consequently the signals that would have been transmitted to the quadriceps. ${ }^{30}$

Butler et $\mathrm{al}^{31}$ also found an association between arthritis and poorer mobility. These authors asserted that aging impaired the stair negotiation ability remarkably earlier and more aggressively among females than among males.

As a function of the data discussed earlier, we are still in doubt as to the determinants of the greater mobility limitation exhibited by females, which might be related not only to gender and obesity but also to the larger prevalence of musculoskeletal disease in the female gender.

This study points the importance to include muscle strength evaluation in the primary care, which could be done by a simple question: do you have any difficulty in climbing up or down stairs?

This study has some strengths: it was a population-based study and not a convenience sample. It analyzed an outcome that is easy to assess by health professionals in developing countries where resources are scarce in the health system.

In addition, it included some important covariates of comorbidities, such as depression. Thus, multivariate analysis is closer to real life.

The present study has some limitations. First, its crosssectional design does not allow for the establishment of temporal relationships between stair negotiation difficulty and the investigated independent variables. However, crosssectional studies are useful for evaluations of the burden of disability in a population and the factors associated with existing cases. However, this type of study is susceptible to survival bias, resulting in underestimation of the associations. Second, people from the original sample who died were not reposed by other people in the study. However, the percentage of the losses was statistically acceptable, and the association between body composition, comorbidities and the ability to negotiate with stairs probably was not significantly changed by this limitation. Another weakness is that comorbidities were self-reported, and the way the questions on COPD and HF were asked might have led to imprecision in the calculation of the corresponding prevalence rates. Third, regarding the study methods, the BIA analyzer used did not allow measurement of the lean mass independent of the body fat. Nevertheless, the correlation between BIA values obtained with this analyzer was assessed by other authors and rated good. ${ }^{32}$ In the present study, the measurements were analyzed as quartiles values instead of absolute values for comparison to reference values; thus, the shortcomings of analyzer probably did not exert a significant influence on the results. BIA was selected for the present primary care-centered epidemiological study because it was the first-choice method for household surveys.

The data obtained in the present study should not make clinicians lose sight of what really matters concerning the quality of life of older adults (ie, improvement in their capacity to perform daily activities and functional independence). To achieve these goals, there are necessary integrated actions that include maintaining a satisfactory nutritional status, muscle strength and aerobic capacity, rational use of medicines and control of chronic degenerative diseases, mental health and the social environment.

Although the most accurate definition of sarcopenia is not yet available, there is sufficient scientific evidence to make health care providers and the overall population aware of the relevance of maintaining muscle strength.

Measurement of the muscle mass is probably less important than strength measurement. Function assessments are important in the clinical care of older adults like a précoce signal of loss of muscle strength. Stair negotiation difficulty probably represents an early stage of motor disability for most people. ${ }^{3,4}$ Simple questions, such as "do you have some difficulty walking on stairs?", may be asked and are useful in a primary care setting.

In primary care attention, we must be attentive to preserve FC. This includes both trying to maintain muscle strength and treat important comorbidities such as depression and lower limb pain.

We suggest that future studies include an assessment of the waist circumference in addition to BMI and body composition because this measurement provides information on the fat distribution pattern.

\section{Acknowledgment}

The present study was funded by the Brazilian National Council for Scientific and Technological Development (Conselho Nacional de Desenvolvimento Científico e Tecnológico - CNPq) under grant number 150173/2013-0.

\section{Disclosure}

The authors report no conflicts of interest in this work.

\section{References}

1. Camara FM, Gerez AG, de Jesus Miranda ML, Velardi M. Capacidade funcional do idoso: formas de avaliação e tendências. [Elderly functional capacity: types of assessment and trends]. Acta Fisiatr. 2008;15(4): 249-256.

2. Fried LP, Bandeen-Roche K, Chaves P, Johnson BA. Preclinical mobility disability predicts incident mobility disability in older women. J Gerontol A Biol Sci Med Sci. 2000;55(1):M43-M52.

3. Chen H-Y, Wang C-Y, Lee M-Y, Tang P-F, Chu Y-H, Suen M-W. A hierarchical categorisation of tasks in mobility disability. Disabil Rehabil. 2010;32(19):1586-1593. 
4. Yeh C-J, Wang C-Y, Tang P-F, Lee M-C, Lin H-S, Chen H-Y. Hierarchy of higher-level physical functions: a longitudinal investigation on a nationally representative population of community-dwelling middle-aged and elderly persons. Disabil Rehabil. 2012;34(15): 1271-1276.

5. Oh-Park M, Wang C, Verghese J. Stair negotiation time in communitydwelling older adults: normative values and association with functional decline. Arch Phys Med Rehabil. 2011;92(12):2006-2011.

6. Cruz-Jentoft AJ, Baeyens JP, Bauer JM, et al; European Working Group on Sarcopenia in Older People. Sarcopenia: European consensus on definition and diagnosis: report of the European Working Group on sarcopenia in older people. Age Ageing. 2010;39(4):412-423

7. Clark BC, Manini TM. Functional consequences of sarcopenia and dynapenia in the elderly. Curr Opin Clin Nutr Metab Care. 2010; 13(3):271-276.

8. Derbré F, Gomez-Cabrera MC, Nascimento AL, et al. Age associated low mitochondrial biogenesis may be explained by lack of response of PGC-1 $\alpha$ to exercise training. Age. 2012;34(3):669-679.

9. Roubenoff R. The "cytokine for gerontologists" has some company. J Gerontol Biol Sci Med Sci. 2014;69(2):163-164.

10. Pereira LS, Narciso FM, Oliveira DM, et al. Correlation between manual muscle strength and interleukin-6 (IL-6) plasma levels in elderly community-dwelling women. Archives of Gerontology and Geriatrics. 2009;48:313-316.

11. Santos M, Gomes W, Pereira D, et al. Muscle strength, muscle balance, physical function and plasma interleukin-6 (IL-6) levels in elderly women with knee osteoarthritis (OA). Arch Gerontol Geriatr. 2011; 52(3):322-326.

12. Nilwik R, Snijders T, Leenders M, et al. The decline in skeletal muscle mass with aging is mainly attributed to a reduction in type II muscle fiber size. Exp Gerontol. 2013;48(5):492-498.

13. Jang YC, Van Remmen H. Age-associated alterations of the neuromuscular junction. Exp Gerontol. 2011;46(2):193-198.

14. Souza RKT, Bortoletto MSS, Loch MR, et al. Prevalência de fatores de risco cardiovascular em pessoas com 40 anos ou mais de idade, em Cambé, Paraná (2011): estudo de base populacional. [Prevalence of cardiovascular risk factors in people aged 40 years or more from the city of Cambé, PR, Brazil (2011): a population-based study]. Epidemiol Serv Saúde. 2013;22(3):435-444.

15. Kyle UG, Bosaeus I, De Lorenzo AD, et al; Composition of the ESPEN Working Group. Bioelectrical impedance analysis - part I: review of principles and methods. Clin Nutr. 2004;23(5):1226-1243.

16. Studenski SA, Peters KW, Alley DE, et al. The FNIH sarcopenia project: rationale, study description, conference recommendations, and final estimate. J Gerontol A Biol Sci Med Sci. 2014;69(5): $547-558$.

17. Silveira EA, Kac G, Barbosa LS. Prevalência e fatores associados à obesidade em idosos residentes em Pelotas, Rio Grande do Sul, Brasil: classificação da obesidade segundo dois pontos de corte do índice de massa corporal. [Obesity prevalence and associated factors in the elderly in Pelotas, Rio Grande do Sul State, Brazil: obesity classifi cation according to two cutoff points for body mass index]. Cad Saude Publica. 2009;25(7):1569-1577.
18. Fess EE. Grip Strength. 2nd ed. Chicago: American Society of Hand Therapists; 1992.

19. Roberts HC, Denison HJ, Martin HJ, et al. A review of the measurement of grip strength in clinical and epidemiological studies: towards a standardised approach. Age Ageing. 2011;40(4):423-429.

20. Neto LSS, Karnikowiski MG, Tavares AB, Lima RM. Associação entre sarcopenia, obesidade sarcopênica e força muscular com variáveis relacionadas de qualidade de vida em idosas. [Association between sarcopenia, sarcopenic obesity, muscle strength and quality of life variables in elderly women]. Rev Bras Fisioter. 2012;16(5):360-367.

21. Dodds RM, Syddall HE, Cooper R, et al. Grip strength across the life course: normative data from twelve British studies. PLoS One. 2014;9(12):e113637.

22. Hughes VA, Frontera WR, Roubenoff R, Evans WJ, Singh MA. Longitudinal changes in body composition in older men and women: role of body weight change and physical activity. Am J Clin Nutr. 2002; 76(2):473-481.

23. Cesari M, Pahor M, Lauretani F, et al. Skeletal muscle and mortality results from the InCHIANTI study. J Gerontol A Biol Sci Med Sci. 2009; 64A(3):377-384.

24. Synder AR, Parsons JT, Valovich McLeod TC, et al. Using disablement models and clinical outcomes assessment to Enab evidence-based athletic training practice, part I: disablement models. J Athl Train. 2008; 43(4):428-436

25. Savage P, Shaw AO, Miller MS, et al. Effect of resistance training on physical disability in chronic heart failure. Med Sci Sports Exerc. 2011; 43(8): 1379.

26. Jenkins KR. Obesity's effects on the onset of functional impairment among older adults. Gerontologist. 2004;44(2):206-216.

27. Georgiadou P, Adamopoulos S. Skeletal muscle abnormalities in chronic heart failure. Curr Heart Fail Rep. 2012;9(2):128-132.

28. Rolland Y, Lauwers-Cances V, Cristini C, et al. Difficulties with physical function associated with obesity, sarcopenia, and sarcopenic-obesity in community-dwelling elderly women: the EPIDOS (EPIDemiologie de l'OSteoporose) study. Am J Clin Nutr. 2009;89(6):1895-1900.

29. Matthews MM, Hsu FC, Walkup MP, Barry LC, Patel KV, Blair SN. Depressive symptoms and physical performance in the lifestyle interventions and independence for elders pilot study. J Am Geriatr Soc. 2011;59(3):495-500.

30. Kam Z, JMD D. Nível de atividade física, dor e edema e suas relações com a disfunção muscular do joelho de idosos com osteoartrite. [Physical Activity Levels, Pain and Swelling and Their Relationships with Knee Muscle Dysfunction in Elderly People with Osteoarthritis]. Rev Bras Fisioter. 2006;10(3):279-284.

31. Butler AA, Menant JC, Tiedemann AC, Lord SR. Age and gender differences in seven tests of functional mobility. J Neuroeng Rehabil. 2009;6(1):1

32. Rodrigues MN, Silva SC, Monteiro WD, Farinatti PTV. Estimativa da gordura corporal através de equipamentos de bioimpedância, dobras cutâneas e pesagem hidrostática. [Comparison of body fat estimation by bioelectric impedance, skinfold thickness, and underwater weighing]. Rev Bras Med Esporte. 2001;7(4):125-131.
Clinical Interventions in Aging

\section{Publish your work in this journal}

Clinical Interventions in Aging is an international, peer-reviewed journal focusing on evidence-based reports on the value or lack thereof of treatments intended to prevent or delay the onset of maladaptive correlates of aging in human beings. This journal is indexed on PubMed Central, MedLine,

\section{Dovepress}

CAS, Scopus and the Elsevier Bibliographic databases. The manuscript management system is completely online and includes a very quick and fair peer-review system, which is all easy to use. Visit http://www.dovepress. com/testimonials.php to read real quotes from published authors. 